\title{
Understanding and Design Catalysts from Molecular to Material Scale: One of the Five Grand-Challenges for Catalysis at the 13th European Congress on Catalysis
}

\author{
Elena Groppo ${ }^{1} \cdot$ Stian Svelle ${ }^{2} \cdot$ Dirk deVos ${ }^{3}$ \\ Published online: 1 September 2018 \\ (c) Springer Science+Business Media, LLC, part of Springer Nature 2018
}

This special issue contains a selection of articles in relation to the 13th European Congress on Catalysis held in the wonderful city of Florence from 27th to 31st August 2017. The theme of the conference, "A bridge to the future", focused the attention to the crucial roles of catalysis science and technology in enabling our sustainable future. The scientific program included world leading plenary and keynote speakers, more than 200 regular oral contributions and over 1600 poster presentations, from almost 60 different countries. It was organized in five thematic sessions dedicated to discuss, in an integrated view, five grand-challenges for catalysis, namely: (1) catalysis to address the evolving energy and chemical scenario, that was co-chaired by Alessandra Beretta (Politecnico of Milan, Italy) and Johannes Lercher (TU München, Germany); (2) catalysis for a cleaner and sustainable future, co-chaired by Ilenia Rossetti (University of Milan, Italy), Lukas Goossen and Martin Mühler (University of Bochum, Germany); (3) addressing catalysis complexity, co-chaired by Alessandro Scarso (University of Venice, Italy) and Emiel Hensen (University of Eindhoven, The Netherlands); (4) understanding and design catalyst from molecular to material scale, co-chaired by Elena Groppo (University of Turin, Italy), Stian Svelle (University of Oslo, Norway) and Dirk deVos (KU Leuven, Belgium); (5) expanding catalysis concepts, co-chaired by Barbara Bonelli (Politecnico of Turin, Italy) and Marco Daturi (University of

Elena Groppo

elena.groppo@unito.it

1 Department of Chemistry, NIS Centre and INSTM, University of Turin, Via G. Quarello 15/A, 10135 Torino, Italy

2 Department of Chemistry, University of Oslo, P.O. Box 1033, Blindern, 0315 Oslo, Norway

3 Centre for Surface Chemistry and Catalysis, Dept M2S, K.U. Leuven, Celestijnenlaan 200F, Post Box 2461, 3001 Leuven, Belgium
Caen, France). A sixth session was added, having a transversal character, namely (6) Industrial catalysis, co-chaired by Giuseppe Bellussi and Paolo Pollesel (ENI).

Topic 4 was devoted to the understanding and designing of catalysts from molecular to material scale. This implies the development and application of new approaches in catalysts synthesis and characterization and the understanding of reaction mechanisms, including the adoption of in-situ and operando methods, theory and modelling of catalysts functions and surface science approaches. As chair-persons of Session 4, we received more than 350 excellent contributions, covering a wide range of subjects, among which: (a) metal-oxide based catalysts and related systems; (b) photocatalysts; (c) electrocatalysts (see e.g. "Design and investigation of molybdenum modified platinum surfaces for modeling of CO tolerant electrocatalysts" by Borbath et al.); (d) acid catalysts; (e) single-site catalysts (see e.g. "Determining $\mathrm{Cu}$-speciation in the $\mathrm{Cu}-\mathrm{CHA}$ zeolite catalyst: the potential of Multivariate Curve Resolution analysis of in situ XAS data" by Borfecchia et al. and "VariableTemperature XAFS Analysis of $\mathrm{SiO}_{2}$-Supported Pd-Bisphosphine Complexes with/without Co-Immobilized Organic Functionality" by Motokura et al.); (f) active sites in confined spaces (see e.g. "Pd(II)-Ni(II) pyrazolate framework as active and recyclable catalyst for the hydroamination of terminal alkynes" by Cirujano et al. and "Hierarchical porosity tailoring of sol-gel derived $\mathrm{Pt} / \mathrm{SiO} 2$ catalysts" by SierraSalazar et al.); (g) mono- and bi- metallic nanoparticles (see e.g. "Surface Segregation in Au Ag alloys investigated by Atom Probe Tomography" by Gilis et al., "Graphene filmsupported oriented 1.1.1 gold (0) versus 2.0.0 copper(I) nanoplatelets as very efficient catalysts for coupling reactions" by Parvulescu, Garcia et al., and " $\mathrm{CO}$ oxidation at $\mathrm{SnO}_{2}$ / $\mathrm{Pt}_{3} \mathrm{Sn}$ (111) interfaces" by Vandichel et al.), (h) catalysts for olefin production and conversion (see e.g. The effect of Alalkyls on the Phillips catalyst for ethylene polymerization: the case of diethylaluminum ethoxide, by Groppo et al.), (i) 
hydrotreating catalysts (see e.g. Impact of citric acid on the impregnation of $\mathrm{CoMoP} / \gamma-\mathrm{Al}_{2} \mathrm{O}_{3}$ catalysts: time and spatially resolved MRI and Raman Imaging study by Delpoux et al.); (l) Fisher-Tropsch catalysts; (m) catalysis in the liquid phase; (n) innovative approaches in catalysis (e.g. "Continuous wave and pulse EPR characterization of open-shell $\mathrm{Ti}^{3+}$ ions generated in hybrid $\mathrm{SiO}_{2}-\mathrm{TiO}_{2}$ monoliths" by Chiesa et al., and "A novel Raman setup based on magnetic-driven rotation of sample" by Signorile et al.).
The here collected contributions represent the state-ofthe-art on catalysis research but at the same time offer some perspectives of new trends and opportunities for catalysis in the next decades. We have enjoyed reading these papers as much as we appreciated all the aspects of the Congress in Florence, both as organizers and as participants ourselves. We wish also the reader will find this Special Issue interesting and inspiring. 